\title{
DIÁLOGOS ENTRE GÊNERO, SAÚDE E DIREITO EDUCATIVO: COLOCANDO EM ANÁLISES AS DIRETRIZES CURRICULARES DA EDUCAÇÃO
}

\author{
DIÁLOGOS ENTRE GÉNERO, SALUD Y DERECHO EDUCATIVO: \\ COLOCANDO EN ANÁLISIS LAS DIRECTRICES CURRICULARES DE LA \\ EDUCACIÓN
}

\author{
DIALOGUES BETWEEN GENDER, HEALTH AND EDUCATIONAL LAW: \\ PLACING IN ANALYSIS THE CURRICULAR GUIDELINES OF EDUCATION
}

\author{
Bruna SORENSEN ${ }^{1}$ \\ Eliane CADONÁ2 ${ }^{2}$ \\ Valesca BRASIL COSTA ${ }^{3}$
}

RESUMO: No presente artigo, discorremos sobre as temáticas gênero, saúde e promoção de cidadania, por intermédio da análise das Diretrizes Curriculares da Educação Nacional. Com esta pesquisa, problematizamos a produção de sentidos, no que tange às temáticas escolhidas, com fins de colocar em análise que noções de sujeito e de mundo materiais oficiais do Ministério da Educação disponibilizam para o exercício de práticas educacionais. Fizemos uso de aportes teóricos relacionados ao Direito Educativo, aos Estudos de Gênero de inspiração pós-estruturalista e ao Construcionismo Social. As diretrizes, entendidas como materiais de domínio público, foram analisadas por intermédio da Análise de Discurso proposta por Mary Jane Spink. Com o presente trabalho, concluímos que as Diretrizes apontam para uma concepção de sujeito e de mundo em um constante processo de construção, noção esta atrelada à promoção de cidadania e aos preceitos dos/as autores/as que nortearam este estudo. Inspiradas nesta pesquisa, levantamos o questionamento de como os/as atores/as que colocam em prática tais ações em seus contextos educacionais vivenciam tais Diretrizes, tendo em vista que essa lógica problematizadora, impressa nos materiais em análise, nem sempre compactua com as noções de sujeito e de mundo vivenciadas pelas comunidades em seus cotidianos.

PALAVRAS-ChAVE: Gênero. Saúde. Direito educativo. Políticas públicas de educação.

\footnotetext{
${ }^{1}$ Universidade Regional Integrada do Alto Uruguai e das Missões (URI), Frederico Westphalen - RS Brasil. Residente Multiprofissional em Cardiologia no Hospital da Cidade, em Passo Fundo. Bacharel em Psicologia. ORCID: <http://orcid.org/0000-0001-5164-2730>. E-mail: bruna_sorensen@hotmail.com.

${ }^{2}$ Universidade Regional Integrada do Alto Uruguai e das Missões (URI), Frederico Westphalen - RS Brasil. Docente. Doutora em Psicologia pela Pontifícia Universidade Católica do Rio Grande do Sul (PUCRS). ORCID: <http://orcid.org/0000-0003-3988-9786>. E-mail: eliane@uri.edu.br.

${ }^{3}$ Universidade Regional Integrada do Alto Uruguai e das Missões (URI), Frederico Westphalen - RS Brasil. Docente. Doutora em Educação pela Universidade do Vale do Rio dos Sinos (Unisinos). ORCID: <http://orcid.org/0000-0002-3679-0273>.E-mail: valescacosta@ gmail.com.
} 
RESUMEN: En el presente artículo, discordamos sobre las temáticas género, salud y promoción de ciudadanía, por intermedio del análisis de las Directrices Curriculares de la Educación Nacional. Con esta investigación, problematizamos la producción de sentidos, en lo que se refiere a las temáticas escogidas, con fines de poner en análisis que nociones de sujeto y de mundo materiales oficiales del Ministerio de la Educación ponen a disposición para el ejercicio de prácticas educativas. Hicimos uso de aportes teóricos relacionados al Derecho Educativo, a los Estudios de Género de inspiración post-estructuralista y al Construccionismo Social. Las directrices, entendidas como materiales de dominio público, fueron analizadas por intermedio del Análisis de Discurso propuesto por Mary Jane Spink. Con el presente trabajo, concluimos que las Directrices apuntan hacia una concepción de sujeto y de mundo en un constante proceso de construcción, noción esta vinculada a la promoción de la ciudadanía y a los preceptos de los / as autores / as que orientaron este estudio. Inspiradas en esta investigación, planteamos el cuestionamiento de cómo los / as actores / as que ponen en práctica tales acciones en sus contextos educativos vivencian tales Directrices, teniendo en vista que esa lógica problematizadora, impresa en los materiales en análisis, no siempre comprimen con las nociones de sujeto y de mundo vivenciadas por las comunidades en sus cotidianos.

PALABRAS CLAVE: Género. Salud. Derecho educativo. Políticas públicas de educación.

ABSTRACT: In this article, we will discuss the thematic about gender, health and promotion of citizenship, by means of analysis of the Curriculum Guidelines of National Education. With this research, we problematize the production of meanings, in relation to the thematic chosen, with the purpose of putting in analysis that notions of subject and of world official materials of the Ministry of Education makes available for the exercise of educational practices. We make use of theoretical contributions related to Education Law, to Gender Studies of post-structuralist inspiration, and Social Constructionism. The guidelines, understood as public domain materials, were analyzed by means of Discourse Analysis proposed by Mary Jane Spink. With the present work, we conclude that the Guidelines point to a conception of subject and world in a constant process of construction, notion is linked to the promotion of citizenship and the precepts of the authors that guided this study. Inspired by this research, we raise the question of how the authors that put these actions into practice in their educational contexts experience such Guidelines, experience such Guidelines, considering that this problematizing logic, printed on the materials under analysis, not always compact with the notions of subject and world experienced by the communities in their daily lives.

KEYWORDS: Gender. Health. Educational law. Public policy of education.

\section{Introdução}

Neste estudo, as temáticas Gênero, Saúde e Promoção de Cidadania foram analisadas, por intermédio do estudo do discurso presente nas Diretrizes Curriculares para a Educação Básica (BRASIL, 2013). O intuito da referida pesquisa foi 
problematizar a noção de sujeito impressa em meio aos materiais, no que tange à Educação Formal. Os aportes teóricos que nortearam este estudo foram o Direito Educativo (ESCOBAR, 2017), os Estudos de Gênero de inspiração pós-estruturalista (BUTLER, 2008; SCOTT, 2005) e o Construcionismo Social (GERGEN; GERGEN, 2009).

Neste artigo, traremos, primeiramente, algumas discussões pertinentes para, na sequência, trazer a análise dos principais resultados encontrados.

\section{O Ensino de saúde, o exercício da cidadania e a necessidade de políticas públicas de educação e de saúde}

O entendimento de saúde, tomado em sua complexidade, exige uma leitura que deve ir além da tradicional concepção higienista - a qual consideramos um tanto limitada - de que seu significado está apenas relacionado à ausência de doença. Propõese, pois, com este estudo dedicar-se a fazer uma leitura mais integrada do tema em questão.

Dessa maneira, o conceito de saúde aqui trabalhado leva em conta a relação direta da pessoa com a sociedade em que ela está inserida e pela sua potencialidade de defender a vida.

Assim, este trabalho possui função importante, uma vez que dialoga interdisciplinarmente com as áreas da Educação, Psicologia e Direito, tomando como base o exercício da cidadania através do acesso ao ensino de saúde, uma temática que se mostra carente de estudos. A obra "A era dos Direitos" ampara o antes exposto, uma vez que a garantia e o exercício dos direitos é um fenômeno social e, assim sendo, está intimamente relacionado à realização e ao desenvolvimento pleno do/a cidadão/a, como considerado abaixo:

Também os direitos do homem são, individualmente um fenômeno social. Ou, pelo menos, são também fenômeno social: e, entre os vários pontos de vista de onde podem ser examinados (filosófico, jurídico, econômico, etc.), há lugar para o sociológico, precisamente o da sociologia jurídica (BOBBIO, 2004, p. 63).

É fundamental destacar que este momento é dedicado a um estudo pontual, da possibilidade e da necessidade do exercício da cidadania através da saúde, de maneira que, para embasar este trabalho, é interessante considerar a importância da Constituição Federal de 1988, também chamada de "Constituição Cidadã", que resguarda e defende 
como nenhuma outra Constituição anterior brasileira, o exercício da cidadania e ainda dos direitos sociais, garantidos no Artigo $6^{\circ}$ da Constituição federal de 1988, como observado abaixo:

Art. $6^{\circ}$ São direitos sociais a educação, a saúde, a alimentação, o trabalho, a moradia, o transporte, o lazer, a segurança, a previdência social, a proteção à maternidade e à infância, a assistência aos desamparados, na forma desta Constituição.

Assim, o antes considerado destaca que a função dos direitos sociais, e especialmente do direito à educação e à saúde, legitima que o/a cidadão/a, para se desenvolver plena e socialmente, deve ter garantido pelo Estado o acesso à educação e à saúde, bem como acesso aos meios que as promovam, orientando este/a cidadão/a de que o conceito de saúde vai além da ausência de doença e que envolve um complexo de ações propiciadoras de seu desenvolvimento pleno como ser humano, dentro da sociedade em que está inserido/a.

Acreditamos, mediante o exposto, ser preciso, no campo da Educação e da Saúde, ir além de conceitos produzidos na modernidade e aprofundar estudos apontando que, no que se refere a direitos sociais, o Estado tem papel fundamental na promoção de políticas públicas, que garantam o pleno usufruto desses direitos pelos cidadãos/cidadãs, como bem definido abaixo:

Na modernidade, o termo reporta-se, fundamentalmente, à atividade ou conjunto de atividades que, de uma forma ou de outra, são imputadas ao Estado moderno capitalista ou dele emanam. O conceito de política encadeou-se, assim, ao poder do Estado - ou sociedade política - em atuar, proibir, ordenar, planejar, legislar, intervir, com efeitos vinculadores a um grupo social definido e ao exercício do domínio exclusivo sobre um território e da defesa de suas fronteiras (SHIROMA, 2004, p.7).

Cabe considerar que, embora a definição de política pública seja aparentemente completa, é preciso destacar que o contexto de sua atuação é bem mais amplo e exige ações interdisciplinares, sendo este instrumento fundamental para se chegar ao exercício da cidadania. Assim, este estudo destaca a necessidade que o Brasil tem de direcionar suas políticas públicas, com vistas a possibilitar que o/a cidadão/a seja investido em sua integralidade (BRASIL, 1990).

\section{Gênero e Saúde no campo da Educação Formal}


A articulação entre as temáticas Gênero, Saúde e Promoção de Cidadania, tendo como material de análise as Políticas Públicas de Educação nasce, no âmbito de nossas pesquisas, no intuito de problematizar a produção de subjetividade no espaço da Educação Formal. Desse modo, a necessidade de uma articulação, de caráter interdisciplinar, no campo da discussão de tais documentos, faz-se necessária para uma melhor compreensão do campo em análise.

Compreendemos saúde, com base na Constituição Federal (BRASIL, 1988), na Saúde Coletiva (CADONÁ; SCARPARO; STREY, 2017; CAMPOS et al., 2012, CANGUILHEM, 2011) e no Direito Educativo (ESCOBAR, 2017) como um fenômeno complexo e amplamente atrelado ao conceito de cidadania, tendo em vista a ideia de que, para se ter saúde, há de se ter garantido acesso à moradia, educação, lazer, alimentação, cultura, liberdade de expressão, acesso a bens e serviços ofertados e/ou intermediados pelo Estado, dentre outros (BRASIL, 1988).

Atrelada a esse conceito, a temática Gênero, enquanto campo de estudo que problematiza conceitos históricos e produzidos socialmente como Masculino e Feminino, Inato e Aprendido, traz à tona, desde a criação dos Parâmetros Curriculares Nacionais (BRASIL, 1997), a Orientação Sexual e a Saúde, como temas transversais, como fenômenos que ultrapassam os muros dos conceitos puramente biologicistas, compreendendo tais questões também como políticas, culturais, sempre por se fazer.

Assim, partimos do pressuposto de que, ao demarcarmos a Orientação Sexual e a Saúde como campos interdisciplinares e não exclusivamente biológicos, passamos a ampliar seu território de discussão, o que historicamente não foi possível porque tais espaços sempre foram marcados por uma lógica de ciência linear e positivista, dita neutra e com viés moralista (GERGEN; GERGEN, 2009).

Assim, ao atrelarmos tais noções a esse campo de discussão, por intermédio dos Estudos de Gênero, compreendemos que a promoção de cidadania deve estar amplamente articulada a um trabalho em sala de aula que, acima de tudo, considere, reconheça e respeite as diferenças.

Assim, por intermédio do Construcionismo Social, para formularmos novos modelos de ações que coloquem em análise os moldes conteudistas e fragmentados da escola moderna, precisamos, primeiramente, ter consciência histórica de nossas práticas.

Por intermédio dos Estudos de Gênero, defendemos a ideia de trabalharmos a temática da saúde, no contexto de sala de aula, como um conceito marcado por tempos e lugares, que, historicamente, fixou normas de existir ligadas à heteronormatividade e a 
noções de saúde que compreendiam a noção de masculino e de feminino a uma explicação puramente biológica.

\section{Método}

Este estudo, que seguiu uma epistemologia de caráter qualitativo e documental, teve por intuito colocar em análise discursos de Gênero e Saúde produzidos na contemporaneidade, no cenário das Políticas Públicas. A escolha deste enfoque se deu pelo fato de que, com este tipo de pesquisa, é possível considerar a comunicação do/a pesquisador/a com seu objeto de estudo enquanto parte da produção de conhecimento. Desta forma, reflexões, sentimentos e impressões deste/a em meio ao processo de pesquisa transformam-se em dados que constituirão parte da interpretação. Além disso, a pesquisa qualitativa possui uma grande variedade de métodos que partem de diferentes premissas na busca pelos mais variados objetos, sendo que cada um desses métodos encontrará uma forma diferenciada de compreensão (FLICK, 2004) o que, de certo modo, permite entender o processo de pesquisa inseparável das percepções políticas, culturais e contemporâneas do/a pesquisador/a.

Os documentos escolhidos para a análise, importantes norteadores para a prática diária do/a professor/a, em sala de aula, no contexto da Educação Formal, foram analisados por intermédio da proposta de Análise de Discurso de Mary Jane Spink (1999). A seguir, apresentaremos os resultados encontrados em meio a esta pesquisa.

\section{Análise e discussão dos resultados: as Diretrizes Curriculares e as noções de sujeito no campo da Saúde e do Gênero}

A educação sempre esteve presente, de maneira mais ou menos formal, ao longo do desenvolvimento do homem e da mulher em sociedade, o que tem contribuído para as transformações socioculturais e políticas ao longo dos anos, bem como das diferentes representações que o ser humano construiu sobre si mesmo em sua história.

Assim sendo, ao pensar a educação nesse contexto, não podemos desvinculá-la de seu caráter político/ideológico, tampouco do tempo histórico em que se constitui, uma vez que, também os saberes, técnicas e valores, passados de geração em geração enquanto representações sociais inspiram o sistema educacional e refletem nas políticas públicas e nas questões de gênero, bem como nas formas de promoção de saúde-doença neste contexto e por meio dele. 
Conforme Cadoná, Strey e Scarparo (2015, p.50), saúde é concebida como uma produção social complexa, atravessada por conceitos e práticas e marcada por momentos históricos específicos, sendo que "para ser alcançada, colocada em prática e vivenciada, envolve participação ativa de todos os sujeitos implicados no processo, a saber, usuários/as, movimentos sociais, gestores/as e profissionais". Para tanto, em termos legislativos, a saúde tem como princípios a integralidade, a cidadania e a humanização, apesar de muitos modelos de atenção ainda centrarem o conceito de saúde na ausência de doença, favorecendo um enfoque biologicista pautado em dicotomias.

De modo semelhante, com base na definição feita por Canguilhem (2011), entendemos a doença como sendo um fenômeno que se dá entre as pessoas e de modo variável, de acordo com o modo como o sujeito (político, cultural e histórico) dá sentido a ela, de forma que não podemos nos referir a um distúrbio patológico em si, uma vez que a anormalidade, para o autor, somente pode ser vivenciada em contextos relacionais.

O ensino de saúde tem sido um desafio para a educação, no que se refere à possibilidade de garantir uma aprendizagem efetiva e transformadora de atitudes e hábitos de vida. As experiências mostram que transmitir informações a respeito do funcionamento do corpo e descrição das características das doenças, bem como um elenco de hábitos de higiene, não é suficiente para que os alunos desenvolvam atitudes de vida saudável (BRASIL, 1997, p. 61).

Frente a esse entendimento, o que se pretende atualmente é poder lançar outro olhar para essa questão. Nesse sentido, embora a Organização Mundial da Saúde (OMS) traga um conceito de saúde como "completo bem-estar físico, mental e social e não apenas a ausência de doença", os Parâmetros Curriculares Nacionais (PCNs) criticam tal conceito, à medida que consideram utopia esse "completo bem-estar". Assim, conceituam de maneira dinâmica a saúde, entendendo que ela é uma resultante das relações individuais e coletivas produzidas com o meio físico, social e cultural (BRASIL, 1997). Nesse aspecto, argumentam que, diante da variedade de elementos que determinam as condições de saúde-doença das pessoas, falar nesse processo, "envolve componentes aparentemente tão dispares como a qualidade da água que se consome" (p. 251).

Desse modo, passamos a compreender que os fenômenos saúde/doença, bem como todos os seus determinantes, fazem parte do processo de vida de forma relacional, o que nos impede de dizer que a saúde passa a ser simplesmente ausência de doença. É, 
pois, o modo como as pessoas e as sociedades se relacionam com e vivenciam tudo isso que talvez dirá sobre sua condição de saúde (BRASIL, 1997).

De modo semelhante, concordamos com essas colocações, à medida que nossa discussão também pretende romper com a lógica do discurso higienista - que coloca a saúde e a doença como opostos - e se propõe a pensar a saúde como um fenômeno complexo, buscando, desse modo, a superação de um modelo tecnicista ligado à doença (CADONÁ; STREY; SCARPARO, 2015, p.49), e aceita o entendimento da saúde como uma luta pela ampliação do uso das potencialidades de cada pessoa e da sociedade (BRASIL, 1998).

Assim, compreende-se, de maneira geral, que relacionar os conceitos de saúde às diferentes áreas de educação permite uma reconstrução das diferentes definições históricas e sociais que definiram tal conceito. Ainda, consiste em oferecer uma visão mais ampla do que é saúde, à medida que relaciona várias dimensões do aprendizado, tornando mais vivencial sua compreensão.

Quanto aos objetivos gerais para o ensino fundamental, os PCNs destacam que a educação para saúde cumprirá seus objetivos ao conscientizar os/as alunos/as para o direito à saúde, sensibilizá-los para a busca permanente de compreensão de seus determinantes e capacitá-los/as para a utilização de medidas práticas de promoção, proteção e recuperação da saúde ao seu alcance, esperado que, ao final do ensino fundamental, os/as alunos/as sejam capazes de compreender que a saúde é um direito de todos/as, e que a condição de saúde é produzida nas relações com o meio físico, econômico e sociocultural (BRASIL, 1997).

Além disso, trata-se de conhecer e utilizar formas de intervenção individual e coletiva sobre os fatores desfavoráveis à saúde; conhecer formas de acesso aos recursos da comunidade e as possibilidades de utilização dos serviços e adotar hábitos de autocuidado, respeitando as possibilidades e limites do próprio corpo. Para atender aos objetivos, conforme destacam os documentos dos PCNs (BRASIL, 1997), os conteúdos foram divididos em dois grupos: O Autoconhecimento para o Autocuidado e Vida Coletiva. O primeiro - Autoconhecimento para o Autocuidado - trata da introdução de conhecimentos sobre o funcionamento do corpo humano, a fim de formar sujeitos conscientes do processo saúde/doença que possam se conhecer e se cuidar, valorizando sua identidade e características pessoais. O segundo grupo - Vida Coletiva - aborda, por sua vez, noções mais amplas do conceito de saúde, permitindo à criança compreender os atravessamentos presentes em seu contexto social, que implicam na 
saúde. No segundo ciclo, tendo em vista a faixa etária dos/as alunos/as, pretende-se trabalhar os mesmos grupos de conteúdos, contudo, partindo de perspectivas diferentes. Nesse aspecto, no que tange ao Autoconhecimento para o Autocuidado, a finalidade gira em torno de "possibilitar aos alunos o entendimento de que saúde tem uma dimensão pessoal, que se expressa, no espaço e no tempo de uma vida, pelos meios de que cada ser humano dispõe para trilhar seu caminho em direção ao bem-estar físico, mental e social" (BRASIL, 1997, p. 275).

Nessa perspectiva, "articulamos o conceito de cuidado a uma política de existência que olha para o humano em sua integralidade, com formulação e exercício de políticas públicas pautadas na lógica da promoção da cidadania." (CADONÁ; STREY; SCARPARO, 2015, p. 49), o que requer compreender que, para realizar uma análise dos sentidos de sujeito, de saúde e de cuidado, bem como para problematizar as relações de gênero no campo da educação, precisamos considerar a interação dos fatores culturais, sociais, políticos e históricos tanto com relação às práticas sociais quanto com relação à legitimação desses discursos, por meio das Políticas Públicas, por exemplo.

No que se refere à Educação, olhamos para o início das propostas no âmbito das políticas públicas, tomando como ponto de partida a Constituição Federal (CF) que, como conjunto de normas controladoras instituídas pelo Estado, funciona como instrumento que orienta e legitima transformações sociais.

De forma a dar continuidade a esse movimento de forças, disposto a mudar os rumos da educação nacional e, com fins de reforçar definições presentes na $\mathrm{CF}$, em 1996 é criada a Lei que estabelece as diretrizes e bases da educação nacional, Lei $N^{\circ}$ 9.394, de 20 de dezembro de 1996, também chamada de LDB (BRASIL, 1996).

Quanto à presença de tal tema nos currículos escolares, cabe destacar que, de acordo com os Parâmetros Curriculares, desde o século XIX, de algum modo, fala-se sobre a saúde por meio da educação. Contudo, os conteúdos demonstram o caráter biológico e dicotômico, que sempre envolveu as discussões a esse respeito, à medida que estabelecia uma estreita relação entre o "doente" e o "agente causal", excluindo e limitando potentes focos de discussão, que olhassem para as representações macros sociais envolvidas (BRASIL, 1997).

Notamos que a noção de cuidado, como algo indissociável ao ato de educar, é um discurso muito presente nas Diretrizes Curriculares Nacionais. Entretanto, as mesmas não aprofundam o que entendem por cuidado na educação, dando margem a interpretações por parte do/a leitor/a, e assim, assume-se o risco de este conceito ser 
abordado de forma rasa e reducionista. Então, vemos como algo muito necessário lançar um olhar da psicologia, a fim de contribuir com as discussões acerca de um tema tão pertinente.

Entendemos que cuidado na educação pressupõe uma atitude de respeito frente ao sujeito em sua integralidade, buscando formas de trabalhar com o mesmo com o intuito de promover a sua autonomia. Paulo Freire foi um importante teórico, que trouxe algumas considerações importantes sobre as práticas educacionais, partindo de uma perspectiva mais humana e libertária, na qual a educação assume um papel muito importante na construção de um sujeito crítico e autônomo (FREIRE, 1979). Freire (1986 apud OLIVEIRA, 2007, p.10) traz sobre a exploração de novas possibilidades pedagógicas, dizendo:

Até que ponto vai ser possível... Inventar uma pedagogia que não seja a da conversão... Mas a do crescimento, que não se faz sem a transformação da realidade concreta que está gerando injustiças... Vamos cair na dimensão política... Mas... Não a serviço de dominações, mas a serviço da mudança radical da sociedade... Se pensamos numa Pedagogia que ajude a preservação da sociedade tal qual ela está aí, esta sociedade irá continuar a preservar exatamente esta diferença radical entre estes dois mundos.

A "Pedagogia da Presença", corrente que possui como raiz o pensamento do padre Marcelino Champagnat, na qual os/as estudantes têm autonomia para falar, participar, sugerir, mas tudo dentro de uma organização, de disciplina, traz algumas teorizações interessantes com relação à atitude do/a educador/a frente ao/a educando/a. O/a educador/a, ao estabelecer um vínculo com os/as alunos/as, tem que buscar manter um equilíbrio entre proximidade e distância, para que o mesmo seja produtivo. Proximidade para compreender seu educando/a de forma empática e significante, e distância para que possa manter um olhar crítico frente às próprias ações (OLIVEIRA, 2007).

A partir dessas colocações podemos dizer que cuidado dentro da educação consiste em cuidado para não invadir o mundo da criança ou do adolescente, não ultrapassando seu espaço vital, apenas se ele/a houver permitido, caso contrário, isso seria um ato de violência para com o/a aluno/a (FREIRE, 1986 apud OLIVEIRA, 2007).

Em vista disso, é de suma importância abordar essa temática, pois, em se tratando especialmente da Educação Infantil, ao se falar de forma rasa acerca do cuidado, corre-se o risco de acabar por ter esse conceito associado a questões 
relacionadas à maternagem, tendo em vista que em seus primórdios as creches e escolas de educação infantil surgiram como uma forma de substituir os cuidados maternos, na medida em que as mulheres adentravam cada vez mais no mercado de trabalho. A criação de creches foi uma conquista para o movimento de mulheres no Brasil, na medida em que permitiu que a mesma pudesse trabalhar mesmo sendo mãe. A partir daí, as mulheres passaram a se subjetivar de outras formas e não apenas através da maternidade, e essas formas de subjetivação possuem processos de libertação sim, mas também a configuração de novas formas de aprisionamento ligadas a questões de gênero.

É interessante observar o quanto o cuidado com os/as filhos/as e com os afazeres domésticos continuaram a ser vistos como de responsabilidade feminina, por mais que a mulher trabalhe fora. Basta observar as leis trabalhistas para confirmar isto, na medida em que às mulheres fica reservado o direito à licença maternidade de quatro meses para cuidar de seu/sua filho/a, ao passo que os homens têm apenas cinco dias de licença paternidade. Cadoná e Strey (2014) trazem que a maternidade trata-se de um produto cultural que assume características do período sócio-histórico em que se está vivendo, em que as mulheres irão direcionar sua vivência, seus sentimentos e seu entendimento sobre a maternidade, a partir de significados construídos por intermédio de práticas de significação linguística e cultural dos sistemas simbólicos.

[...] o conceito de sujeito materno está pautado na lógica construída na modernidade, em que questões de gênero se ancoram a processos que resultam na desigualdade e na hierarquização em meio a modelos sociais que investem na mulher em uma perspectiva que leva em conta uma essência universal e biológica, colocando-a na posição de cuidadora, educadora, 'por natureza', das crianças (CADONÁ; STREY, 2014, p. 2).

Entretanto, devemos considerar também que a criação de creches e pré-escolas abriu a possibilidade de as mulheres serem subjetivadas de outras maneiras, que não apenas através da maternidade. Borges (2013) destaca que mudanças significativas na trajetória de vida das mulheres tem ocorrido, em que o padrão moderno de mãe e dona de casa está dando espaço para um padrão mais flexível, no qual é permitido às mulheres possibilidades que antes eram exclusivamente masculinas.

Um outro tema também muito relevante para fins de nosso estudo: minoria versus maioria; individualidade, identidade de grupo e igualdade. As Diretrizes Curriculares Nacionais costumam referir-se a grupos como mulheres, negros, crianças 
como minorias, aqueles que representam a diferença. Contudo, se notarmos bem, esses grupos compõem a maior parte das escolas, sendo a "maioria" dentro das mesmas. Isso nos faz refletir sobre como o grupo que "detém a verdade e representa a normalidade" (FOUCAULT, 2002) é composto por homens e brancos, representando estes o padrão a partir do qual o "outro" é definido, então todos que não pertencem a este grupo são tidos como um desvio, aqueles que representam a diferença.

As identidades de grupo são um aspecto inerente à vida social e política, contudo a diferença entre esses grupos se tornam nítidas e, por vezes, problemáticas em contextos políticos específicos (SCOTT, 2005). Tais grupos não são naturalmente diferentes entre si, mas são definidos em sua diferença através da cultura. Portanto para um grupo assumir um caráter de minoria, ele precisa ser socialmente definido como minoria (ROSE, 1972 apud SCOTT, 2005). Arnold Rose (1972 apud SCOTT, 2005, p. 18) discute sobre essas questões dizendo que "uma minoria não precisa ser um grupo tradicional com uma longa história de identificação. Ela pode surgir como resultado das definições sociais que se transformam em um processo de diferenciação política ou econômica".

Joan Scott (2005) complementa o pensamento de Rose ao dizer que, o que faz um determinado grupo ser tido como minoria é a atribuição de um status minoritário a alguma característica inerente a esse grupo, o que, a partir de então, justificaria um tratamento desigual. Como por exemplo, a maternidade já foi utilizada como justificativa para manter as mulheres distantes da vida política, da mesma forma que diferenciações pautadas em raça tornaram-se justificativa para processos de escravização.

Então, vemos assim o quanto processos sociais de diferenciação produzem exclusões, que são então justificadas por meio da biologia ou raça (SCOTT, 2005). Diante dessas considerações, podemos notar quão complexa é a relação entre identidade de grupo, individualidade e igualdade e o quanto, por vezes, ao tentar se promover igualdade acaba-se por reforçar as diferenças que excluem.

Para Palmer (1974, p. 139), "a igualdade requer um ato de escolha, pelo qual algumas diferenças são minimizadas ou ignoradas enquanto que outras são maximizadas e postas a se desenvolver". Falar sobre as relações de gênero, em meio a esse paradoxo que envolve a questão da igualdade e da diferença tem sido, na contemporaneidade, inevitável e, é claro, desafiador. Afinal, a qual/ais sujeito/s nos referimos quando nos propomos a repensar nossas práticas mecanizadas e 
preconceituosas? De que igualdade estamos querendo falar? Que diferenças queremos negar ou salientar? Será que a generalização é a solução? Não dar visibilidade às diferenças não seria uma forma de violência? E como lidar com tudo isso quando falamos em direitos fundamentais?

Precisamos entender que cada sujeito compreende uma série de particularidades. Somos singulares e precisamos ser respeitados por nossas características, ao invés de sermos enquadrados em alguma categoria social, previamente definida, que tente nos limitar para legitimar uma ordem social institucionalizada, tida como natural, embora construída e legitimada pela própria sociedade que a vivencia. Contudo, quais são as diferenças que importam ou não para que as pessoas tenham a garantia de direitos políticos iguais? (CONDORCET, 1976 apud JOAN SCOTT, 2005, p. 16).

\section{Considerações finais}

Este estudo nos proporcionou compreender que as Diretrizes aqui analisadas apontam para uma concepção de sujeito e de mundo em um constante processo de construção, noção esta atrelada à promoção de cidadania e aos preceitos dos/as autores/as que nortearam este estudo. Entretanto, preocupou-nos a presença de noções condizentes com os preceitos constitucionais que, no entanto, não possuem uma discussão aprofundada em meio a tais documentos, movimento este que pode levar o/a leitora/a a uma compreensão equivocada de conceitos que devem ser trabalhados de forma vivencial, no cotidiano também da formação do/a professor/a.

Inspiradas nesta pesquisa, levantamos ainda o questionamento de como os/as atores/as, que colocam em prática tais ações em seus contextos educacionais vivenciam tais Diretrizes, tendo em vista que essa lógica problematizadora, impressa nos materiais em análise, nem sempre compactua com as noções de sujeito e de mundo vivenciadas pelas comunidades em seus cotidianos.

AGRADECIMENTOS: Agradecemos à bolsista do curso de Psicologia pelo auxílio, no decorrer da pesquisa, e na produção deste artigo, Ana Carolina Weselovski da Silva. Nossos agradecimentos também ao PIIC/URI - programa de bolsas de Iniciação Científica. 


\section{REFERÊNCIAS}

BOBBIO, Norberto. A era dos direitos. Rio de Janeiro: Elsevier, 2004.

BORGES, Carolina de Campos. Mudanças nas trajetórias de vida e identidades de mulheres na contemporaneidade. Psicol. Estud., Maringá, 2013, v. 18, n. 1, p. 71-81.

BRASIL. Constituição da República Federativa do Brasil. Brasília, DF: Senado Federal, 1988.

BRASIL. Lei n. 8.080, de 19 de setembro de 1990. Disponível em: <http://www.planalto.gov.br/ccivil_03/leis/18080.htm>. Acesso em: 15 jul. 2017.

BRASIL. Lei de Diretrizes e Bases da Educação Nacional. Brasília, 1996.

BRASIL. Secretaria de Educação Fundamental. Parâmetros Curriculares Nacionais: Introdução aos Parâmetros Curriculares Nacionais/ Secretaria de Educação Fundamental. Brasília: MEC/ SEF,1997.

BUTLER, Judith. Problemas de gênero: feminismo e subversão da identidade (2a ed.). (R. Aguiar). Rio de Janeiro: Civilização brasileira, 2008.

CADONÁ, Eliane.; STREY, Marlene Neves. A produção da maternidade nos discursos de incentivo à amamentação. Revista Estudos Feministas: Florianópolis, 2014. v. 22, n. 2, p. 477-499.

CADONÁ, Eliane.; STREY, Marlene Neves.; SCARPARO, Helena Beatriz K. Conceitos de Saúde e Cuidado na Mídia Impressa Brasileira: uma Análise do Ano de 1990 sob a Perspectiva do Jornal Zero Hora. No prelo. 2015.

CAMPOS, Gastão Wagner de Sousa et al. Tratado de Saúde Coletiva. São Paulo: Hucitec, 2012.

CANGUILHEM, Georges. O normal e o patológico. Rio de Janeiro: Forense Universitária, 2011.

ESCOBAR, Edmundo. EI derecho educativo. Disponível em:

<file:///C:/Users/ADM/Downloads/22.pdf>. Acesso em: 31 maio 2017.

FOUCAULT, Michel. Microfísica do poder. Rio de Janeiro: Edições Graal, 2002.

FREIRE, Paulo. Educação e Mudança. Rio de Janeiro: Paz e Terra, 1979.

GERGEN, Kenneth J.; GERGEN, Mary. O movimento do construcionismo social na psicologia moderna. Interthesis, Florianópolis, v. 6, n. 1, p. 299-325, jan./jul., 2009.

OLIVEIRA, WalterFerreira .Educação social de rua: bases históricas, políticas e pedagógicas. Hist. Cienc. Saúde, Manguinhos, v. 14, n. 1, p. 135-158, 2007. 
SAVIANI, Demerval. Histórias das ideias pedagógicas no Brasil. Campinas, SP:

Autores Associados, 2010.

SCOTT, Joan W. O enigma da igualdade. Revista Estudos Feministas: Florianópolis, 2005.

SHIROMA, Eneida Oto.; MORAES, Maria Cecília M. de.; EVANGELISTA, Olinda. Política Educacional. Rio de Janeiro: DP\&A, 2004.

\section{Como referenciar este artigo}

SORENSEN, B.; CADONÁ, E.; COSTA. V. B. Diálogos entre gênero, saúde e direito educativo: colocando em análises as diretrizes curriculares da educação. Revista Temas em Educação e Saúde, Araraquara, v.14, n.1, p. 16-30, jan./jun., 2018. E-ISSN: 25263471. DOI: 10.26673/rtes.v14.n1.2018.10542

Submetido em: $15 / 10 / 2017$

Aprovado em: 06/03/2017 